\title{
Role of Stress Echocardiography to assess Valvular Heart Disease
}

\author{
Md. Toufiqur Rahman ${ }^{1}$, A K M Monwarul Islam², Mohammad Ullah ${ }^{1}$, Abdullah AI Shafi Majumder ${ }^{2}$ \\ ${ }^{1}$ Department of Cardiology, Col. Malek Medical College, Manikganj, ${ }^{2}$ Department of Cardiology, \\ NICVD, Dhaka
}

(Cardiovasc. j. 2018; 11(1): 67-80)

\begin{abstract}
Introduction:
Echocardiography is attractive on practical grounds in seeking an imaging solution to the limitations of standard exercise stress testing. It is the most widely disseminated and inexpensive technique for non-invasive imaging of the heart. It is "patient friendly" because it is rapidly performed, and is highly versatile, being usable in a variety of environments. In combination with various stressors, echocardiography provides a means of identifying myocardial ischaemia by detection of stress induced wall motion abnormalities. ${ }^{1}$
\end{abstract}

Stress echocardiography is a powerful prognostic tool in chronic coronary disease, after myocardial infarction, and in evaluation of patients before major non-cardiac surgery. It is an accurate test for prediction of functional recovery of dyssynergic zones after revascularization, and also provides valuable physiologic information in patients under consideration for valve surgery. ${ }^{1}$

Doppler echocardiography adds another potentially important dimension to stress echocardiography and using these new emerging fields in valvular heart disease. ${ }^{2}$

Exercise two-dimensional (2D) imaging is used primarily to detect the presence and extent of coronary artery disease by provoking regional ischemia with resulting wall motion abnormalities. The addition of exercise Doppler permits evaluation of valvular function, pulmonary artery pressure, left ventricular outflow tract gradients, and global ventricular systolic and diastolic function. ${ }^{3}$

Stress echo: a historical and socio-economic perspective 2 , 5-10

Tennant and Wiggers demonstrated in 1935 that coronary occlusion immediately resulted in instantaneous abnormality of wall motion. A large body of evidence recognized for the first time that transient dyssynergy was an early, sensitive, specific marker of transient ischaemia, clearly more accurate than ECG changes and pain. In European clinical practice, stress echo has been embedded in the legal and cultural framework of existing European laws and medical imaging referral guidelines. ${ }^{6,7}$ The radiation used for medical examinations and tests is the greatest man made source of radiation exposure. Small individual risks of each test performed with ionizing radiation multiplied by a billion examinations become significant population risks. For this reason, in Europe, both the law and the referral guidelines for medical imaging recommend a justified, optimized, and responsible use of testing with ionizing radiation. European Commission referral guidelines were released in 2001 in application of the Euratom Directive, and explicitly state that a non-ionizing technique must be used whenever it will give information grossly comparable with an ionizing investigation. For instance, "because MRI does not use ionizing radiation, MRI should be preferred when both $\mathrm{CT}$ and MRI would provide similar information and when both are available'. In this perspective of the medical, as well as socio-economic and biological impact of medical imaging, it is imperative to increase all efforts to improve appropriateness ${ }^{8}$ and minimize the radiation burden of stress imaging for the population and the individual patient. The imperative of sustainability of medical imaging is likely to become increasingly important in the near future, also from a US perspective. In the quest for sustainability, stress echocardiography has unsurpassed assets of low cost, absence of environmental impact, and lack of biological effects for both the patient and the operator compared with equally accurate, but less sustainable, competing techniques. ${ }^{1,9,10}$

Address of Correspondence: Dr. Md. Toufiqur Rahman, Department of Cardiology, Col. Malek Medical College, Manikganj, Bangladesh. Emai: drtoufiq1971@gmail.com 
Testing Methods ${ }^{3,11-18}$

A flexible use of exercise, dobutamine, and vasodilator stresses maximizes versatility, avoids specific contraindications of each, and makes it possible to tailor the appropriate test to the individual patient. Among different stresses of comparable diagnostic and prognostic accuracy, semi supine exercise is the most used, dobutamine the best test for viability, and dipyridamole the safest and simplest pharmacological stress and the most suitable for combined wall motion coronary flow reserve assessment.

\section{Table-I}

Targeted parameters valvular functions to be assessed during Stress Echocardiography 4

\begin{tabular}{|c|c|c|c|c|c|c|}
\hline SE indication & SE query & Type of stress & $\begin{array}{c}\text { Sequence of } \\
\text { image acquisition }\end{array}$ & $\begin{array}{l}\text { Levels of image } \\
\text { acquisition }\end{array}$ & SE result & SE report \\
\hline \multicolumn{7}{|l|}{ Native valve disease } \\
\hline \multirow[t]{5}{*}{ Aortic stenosis } & $\begin{array}{l}\text { Severe AS with no } \\
\text { symptoms }\end{array}$ & Exercise & $\begin{array}{l}\text { LV views, colour flow } \\
\text { Doppler for MR, TR CW } \\
\text { Doppler for SPAP, AV } \\
\text { CW Doppler, LVOT PW } \\
\text { Doppler }\end{array}$ & $\begin{array}{l}\text { Baseline, low } \\
\text { workload, peak } \\
\text { exercise }\end{array}$ & $\begin{array}{l}\text { Symptoms } \pm \text { LVEF drop/ } \\
\text { no increase a/o } \\
\text { GLS } \pm \text { RWMA } \pm \text { SPAP } \\
\text { increase } \pm \text { MR } \\
\text { appearance/ } \\
\text { increase } \pm \text { gradient } \\
\text { increase }\end{array}$ & $\begin{array}{l}\text { Severe AS with symptoms/ } \\
\text { pulmonary hypertension/ } \\
\text { dynamic MR/no } \\
\text { contractile reserve/ } \\
\text { inducible ischaemia/ } \\
\text { non-compliant valve }\end{array}$ \\
\hline & \multirow[t]{2}{*}{$\begin{array}{l}\text { Non-severe AS with } \\
\text { symptoms }\end{array}$} & Exercise & $\begin{array}{l}\text { AV CW Doppler, LVOT PW } \\
\text { Doppler, LV views, } \\
\text { Colour flow Doppler for } \\
\text { MR }\end{array}$ & $\begin{array}{l}\text { Baseline, low } \\
\text { workload, peak } \\
\text { exercise }\end{array}$ & $\begin{array}{l}\text { Gradient increase }+ \text { no/min } \\
\text { AVA increase } \pm \mathrm{LVEF} \\
\text { drop/no increase a/o } \\
\text { GLS } \pm \mathrm{RWMA} \pm \mathrm{MR} \\
\text { appearance/ } \\
\text { increase } \pm \mathrm{SPAP} \\
\text { increase }\end{array}$ & $\begin{array}{l}\text { Non-compliant valve/no } \\
\text { contractile reserve/ } \\
\text { inducible ischaemia/ } \\
\text { dynamic MR/pulmonary } \\
\text { hypertension }\end{array}$ \\
\hline & & Dobutamine & $\begin{array}{l}\text { AV CW Doppler, LVOT PW } \\
\text { Doppler, LV views }\end{array}$ & Baseline, low dose & & \\
\hline & \multirow[t]{2}{*}{$\begin{array}{l}\text { Low-flow, low-gradient } \\
\text { AS }\end{array}$} & Dobutamine & $\begin{array}{l}\text { LVOT PW Doppler, AV CW } \\
\text { Doppler, LV views }\end{array}$ & Baseline, low dose & $\begin{array}{l}\text { No/min SV } \\
\text { increase } \pm \text { LVEF drop/no } \\
\text { increase a/o } \\
\text { GLS } \pm \text { gradient } \\
\text { increase } \pm \text { no/min AVA } \\
\text { increase }\end{array}$ & $\begin{array}{l}\text { No flow reserve/no LV } \\
\text { contractile reserve/true- } \\
\text { severe AS }\end{array}$ \\
\hline & & Exercise & $\begin{array}{l}\text { LVOT PW Doppler, AV CW } \\
\text { Doppler, LV views }\end{array}$ & Baseline, low workload & & \\
\hline \multirow[t]{2}{*}{$\begin{array}{l}\text { Primary mitral } \\
\text { regurgitation }\end{array}$} & $\begin{array}{l}\text { Severe MR with no } \\
\text { symptoms }\end{array}$ & Exercise & $\begin{array}{l}\text { LV views, TR CW Doppler } \\
\text { for SPAP }\end{array}$ & $\begin{array}{l}\text { Baseline, low workload, } \\
\text { peak exercise }\end{array}$ & $\begin{array}{l}\text { Symptoms, SPAP } \\
\text { increase, LV EF failure to } \\
\text { increase }\end{array}$ & $\begin{array}{l}\text { Severe MR with } \\
\text { symptoms/pulmonary } \\
\text { hypertension/no } \\
\text { contractile reserve }\end{array}$ \\
\hline & $\begin{array}{l}\text { Non-severe MR with } \\
\text { symptoms }\end{array}$ & Exercise & $\begin{array}{l}\text { Colour flow Doppler for } \\
\text { MR, LV views, TR CW } \\
\text { Doppler for SPAP }\end{array}$ & $\begin{array}{l}\text { Baseline, low workload, } \\
\text { peak exercise }\end{array}$ & $\begin{array}{l}\text { MR increase } \\
\text { No MR increase }\end{array}$ & $\begin{array}{l}\text { Severe MR with symptoms } \\
\text { Symptoms unrelated with } \\
\text { MR }\end{array}$ \\
\hline \multirow[t]{2}{*}{$\begin{array}{l}\text { Secondary mitral } \\
\text { regurgitation }\end{array}$} & $\begin{array}{l}\text { Change in MR severity } \\
\text { with exertion } \pm \text { SPAP } \\
\text { increase }\end{array}$ & Exercise & $\begin{array}{l}\text { Colour flow Doppler for } \\
\text { MR, TR CW Doppler for } \\
\text { SPAP, LV views }\end{array}$ & $\begin{array}{l}\text { Baseline, low workload, } \\
\text { peak exercise }\end{array}$ & $\begin{array}{l}\text { MR increase } \pm \text { SPAP } \\
\text { increase } \\
\text { MR decrease }\end{array}$ & $\begin{array}{l}\text { Dynamic MR, assess } \\
\text { severity } \\
\text { Functional MR }\end{array}$ \\
\hline & $\begin{array}{l}\text { Severe AR with no } \\
\text { symptoms }\end{array}$ & Exercise & LV views & $\begin{array}{l}\text { Baseline, low workload, } \\
\text { peak exercise }\end{array}$ & $\begin{array}{l}\text { Symptoms } \\
\text { EF failure to increase }\end{array}$ & $\begin{array}{r}\text { Severe AR with symptoms/ } \\
\text { no LV contractile reserve }\end{array}$ \\
\hline \multirow[t]{2}{*}{ Aortic Regurgitation } & $\begin{array}{l}\text { Non-severe AR with } \\
\text { symptoms }\end{array}$ & Exercise & $\begin{array}{l}\text { LV views, Colour flow } \\
\text { Doppler for MR, TR CW } \\
\text { Doppler for SPAP }\end{array}$ & $\begin{array}{l}\text { Baseline, low workload, } \\
\text { peak exercise }\end{array}$ & $\begin{array}{l}\mathrm{RWMA} \pm \mathrm{SPAP} \\
\text { increase } \pm \mathrm{MR} \\
\text { appearance/increase }\end{array}$ & $\begin{array}{l}\text { Inducible ischaemia/ } \\
\text { pulmonary hypertension/ } \\
\text { dynamic MR }\end{array}$ \\
\hline & $\begin{array}{l}\text { Severe MS with no } \\
\text { symptoms }\end{array}$ & Exercise & TR CW Doppler for SPAP & $\begin{array}{l}\text { Baseline, low workload, } \\
\text { peak exercise }\end{array}$ & $\begin{array}{l}\text { Symptoms } \pm \text { SPAP } \\
\text { increase }\end{array}$ & $\begin{array}{c}\text { Severe MS with symptoms/ } \\
\text { pulmonary hypertension }\end{array}$ \\
\hline \multirow[t]{2}{*}{ Mitral stenosis } & \multirow[t]{2}{*}{$\begin{array}{l}\text { Non-severe MS with } \\
\text { symptoms }\end{array}$} & Exercise & $\begin{array}{l}\text { TR CW Doppler for SPAP, } \\
\text { MV CW Doppler for } \\
\text { mean gradient }\end{array}$ & $\begin{array}{l}\text { Baseline, low workload, } \\
\text { peak exercise }\end{array}$ & $\begin{array}{l}\text { MV gradient } \\
\text { increase } \pm \text { SPAP } \\
\text { increase }\end{array}$ & Severe MS \\
\hline & & Dobutamine & $\begin{array}{l}\text { MV CW Doppler for mean } \\
\text { gradient }\end{array}$ & Baseline, low dose & & \\
\hline Multivalvular disease & $\begin{array}{l}\text { Discordance in } \\
\text { between symptoms } \\
\text { and severity of valve } \\
\text { disease }\end{array}$ & Exercise & $\begin{array}{l}\text { Combination on the above } \\
\text { depending on } \\
\text { combination of features } \\
\text { at baseline }\end{array}$ & $\begin{array}{l}\text { Baseline, low workload, } \\
\text { peak exercise }\end{array}$ & $\begin{array}{l}\text { Re-evaluate symptoms/ } \\
\text { severity of valve disease }\end{array}$ & $\begin{array}{l}\text { Symptoms due or not to } \\
\text { valve disease }\end{array}$ \\
\hline \multicolumn{7}{|l|}{ Post valve procedures } \\
\hline \multirow[t]{2}{*}{ Aortic valve prosthesis } & \multirow[t]{2}{*}{$\begin{array}{l}\text { Stenosis/PPM with or } \\
\text { without low flow }\end{array}$} & Exercise & $\begin{array}{l}\text { AV CW Doppler, LVOT PW } \\
\text { Doppler, TR CW Doppler } \\
\text { for SPAP, LV views, } \\
\text { Colour flow Doppler for } \\
\text { MR }\end{array}$ & $\begin{array}{l}\text { Baseline, low workload, } \\
\text { peak exercise }\end{array}$ & $\begin{array}{l}\text { Symptoms } \pm \text { gradient } \\
\text { increase }+ \text { no/min } \mathrm{EOA} \\
\text { increase } \pm \mathrm{SPAP} \\
\text { increase } \pm \mathrm{RWMA} \pm \mathrm{MR} \\
\text { appearance/increase }\end{array}$ & $\begin{array}{l}\text { Significant stenosis or } \\
\text { PPM/inducible } \\
\text { ischaemia/dynamic MR }\end{array}$ \\
\hline & & Dobutamine & $\begin{array}{l}\text { AV CW Doppler, LVOT } \\
\text { Doppler, LV views }\end{array}$ & Baseline, low dose & & \\
\hline \multirow[t]{2}{*}{ Mitral valve prosthesis } & \multirow[t]{2}{*}{ Stenosis/PPM } & Exercise & $\begin{array}{l}\text { TR CW Doppler for SPAP, } \\
\text { MV CW Doppler for } \\
\text { mean gradient }\end{array}$ & $\begin{array}{l}\text { Baseline, low workload, } \\
\text { peak exercise }\end{array}$ & $\begin{array}{l}\text { Symptoms } \pm \text { gradient } \\
\text { increase } \pm \text { SPAP } \\
\text { increase }\end{array}$ & Significant stenosis or PPM \\
\hline & & Dobutamine & $\begin{array}{l}\text { MV CW Doppler for mean } \\
\text { gradient }\end{array}$ & Baseline, low workload & & \\
\hline \multirow[t]{2}{*}{ Mitral valve annuloplasty } & \multirow[t]{2}{*}{ latrogenic MS } & Exercise & $\begin{array}{l}\text { TR CW Doppler for SPAP, } \\
\text { MV CW Doppler for } \\
\text { mean gradient }\end{array}$ & $\begin{array}{l}\text { Baseline, low workload, } \\
\text { peak exercise }\end{array}$ & $\begin{array}{l}\text { Gradient increase } \pm \text { SPAP } \\
\text { increase }\end{array}$ & latrogenic MS \\
\hline & & Dobutamine & $\begin{array}{l}\text { MV CW Doppler for mean } \\
\text { gradient }\end{array}$ & Baseline, low workload & & \\
\hline
\end{tabular}


Native Valve Disease

The clinical indications for $\mathrm{SE}$ in native valve disease can be classified into three categories: severe valve disease without symptoms, non-severe valve disease with symptoms, and valve disease with low flow. In all cases, the purpose of the test is to identify the patients in need of intervention, namely those patients with severe valve disease and symptoms, LV systolic dysfunction, or other haemodynamic consequences. Therefore, in severe valve disease without symptoms the main aim of the test is to elicit symptoms, which may not be otherwise appreciated because of sedentary lifestyle. Additionally, the haemodynamic consequences of exertion in the patient with severe valve disease, such as exercise-induced hypotension or arrhythmia, may be uncovered. In non-severe valve disease with symptoms, the main aim of the test is to question whether the valve disease is actually severe, re-grading the severity based on stress-induced changes or a potential dynamic component. In valve disease with low flow, the aim of the test is to determine whether the valve disease is severe based on flow-dependent changes in severity parameters with stress. ${ }^{19-23}$

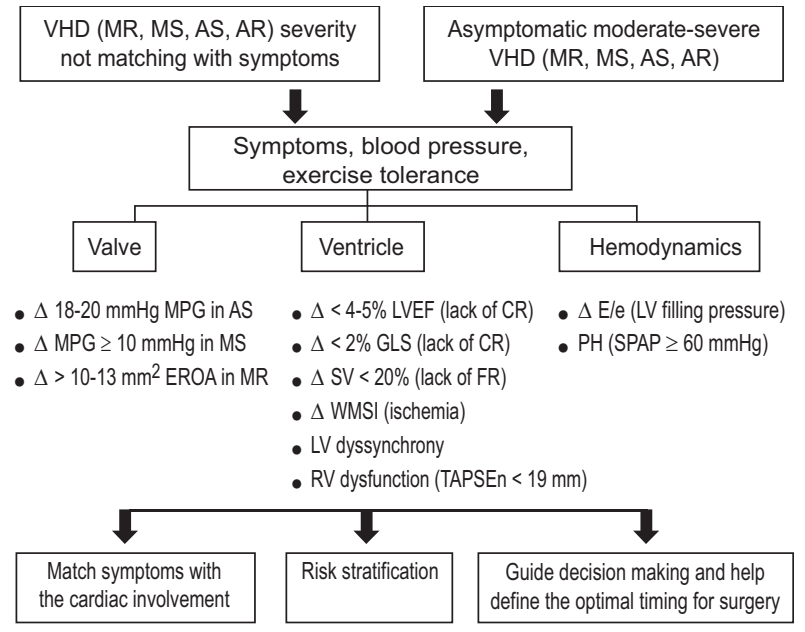

Fig.-1: Usefulness of exercise SE in patients with valvular heart disease (VHD). The three components of VHD consequences are examined allowing individual risk stratification.D, changes from rest to peak exercise;AR, aortic regurgitation;AS, aortic stenosis; GLS, global longitudinal strain; $L V E F$, left ventricular ejection fraction; $M P G$, mean pressure gradient; $M R$, mitral regurgitation; $M S$, mitral stenosis; $R V$, right ventricle;PH, systolic pulmonary hypertension; SPAP, systolic pulmonary artery pressure; TAPSE, tricuspid annulus plane systolic excursion;WMSI, wall motion score index 4

\section{Mitral Regurgitation 4}

The severity of MR can have a dynamic nature, being load dependent or increasing with exercise. Increase in severity during exertion has been reported regardless of etiology. ${ }^{24-29}$ Images should be acquired at baseline and immediately post-exercise when using a treadmill, and at baseline, low workload, and peak exercise when using a supine bicycle. Dobutamine should not be used instead of exercise to assess the dynamic behaviour of MR because its effects on MR severity are not physiologic. One exception to this is when inducible ischaemia is suspected in a patient who cannot complete an exercise test, as ischaemia may be the mechanism of MR. ${ }^{19}$

\section{Primary $M R$}

In patients with primary MR, exercise echocardiography may provoke symptoms and be useful to assess the SPAP response and stratify risk. ${ }^{22,23}$ Although there is less evidence, the test is also reasonable in symptomatic patients with at least moderate MR. The increase in MR severity ( $\geq 1$ grade),dynamic PH (SPAP $\geq$ $60 \mathrm{mmHg}$ ), the absence of contractile reserve $(<5 \%$ increase in $\mathrm{EF}$ or $<2 \%$ increment in global longitudinal strain), and a limited RV contractile recruitment (quantified by tricuspid annular plane systolic excursion (TAPSE) $<18 \mathrm{~mm}$ )are all parameters of poor prognosis. The lack of contractile reserve predicts decrease in LVEF and symptoms at follow-up in medically managed patients; it also predicts post-operative LV systolic dysfunction in surgically treated patients. ${ }^{4,30-42}$

When MR is not severe at rest, the dataset should include colour flow Doppler (to allow off-line quantification of severity by PISA method and vena contracta of the regurgitant jet), MR CW Doppler for quantification of severity by PISA method, TR CW Doppler for estimation of the SPAP, and LV views for global and regional systolic function assessment. Image acquisition should be performed in this order as MR severity and SPAP may decrease immediately on termination of the test. The assessment of MR severity parameters becomes more difficult at heart rates $>115 \mathrm{bpm}$. It is important to scan for TR jet velocity by CW Doppler ideally early during exercise since early increase in SPAP is 
a marker for more significant disease. When MR is severe at rest, there is no need to assess MR severity during stress. Image acquisition should focus on SPAP and LV contractile reserve. ${ }^{4}$

\section{Secondary $M R$}

SE may provide helpful information in patients with the following symptoms and circumstances: shortness of breath on exertion disproportionate to $\mathrm{LV}$ systolic dysfunction or MR severity at rest ${ }^{22,23}$ recurrent and unexplained acute pulmonary edema; ${ }^{22}$ intermediate severity of MR who are scheduled for coronary artery bypass grafting $^{22}$ (to identify those who may benefit from combined revascularization and mitral valve repair), for individual risk stratification, or persistent $\mathrm{PH}$ after mitral valve repair. ${ }^{33}$ Increase in MR severity (increase in ERO $\geq 13 \mathrm{~mm}^{2}$ ) and dynamic $\mathrm{PH}$ (SPAP $\geq 60 \mathrm{mmHg}$ ) are predictors of worse prognosis. ${ }^{43,48}$ Conversely, a decrease in MR severity, often related to recruited LV basal contractile reserve, is a marker of better outcome with medical treatment. $^{29}$

\section{Impact on Treatment}

The current ESC/EACTS guidelines consider combined surgery as a class IIa, level of evidence $\mathrm{C}$, indication in patients with moderate secondary MR, planned coronary artery bypass grafting, shortness of breath, and exercise $\mathrm{PH}$ in the setting of dynamic worsening of secondary $\mathrm{MR}$. In severe primary MR, an $\mathrm{SPAP} \geq 60 \mathrm{mmHg}$ on exertion is a class IIb, level of evidence C, indication for surgery in case of high likelihood of durable repair and low surgical risk. No specific recommendation has been provided in the AHA/ACC guidelines. ${ }^{4,22,23}$

\section{Aortic Regurgitation}

In severe aortic regurgitation (AR), the onset of symptoms heralds a dramatic change in prognosis, with mortality being reported as high as $10-20 \%$ per year. Exercise testing is recommended to reveal symptoms in the patient with severe AR who reports being asymptomatic. ${ }^{23}$ Neither exercise nor dobutamine $\mathrm{SE}$ can be used to re-grade AR severity in the patient with symptoms, because the test-induced increase in heart rate shortens diastole, limiting quantification of AR severity ${ }^{4}$.
Severe Aortic Regurgitation without Symptoms Exercise testing is recommended to reveal symptoms. ${ }^{22}$ Exercise echocardiography can serve this purpose, concomitantly providing LV contractile reserve assessment, but there is limited evidence to support this indication. The lack of contractile reserve ( $<5 \%$ change in LVEF) was found to predict LV systolic dysfunction development at follow-up or post-operatively. Rest and exercise longitudinal function assessment (by TDI parameters) may reveal early signs of LV systolic dysfunction. ${ }^{4,49}$

Non-severe Aortic Regurgitation with Symptoms Exercise testing is recommended to confirm equivocal symptoms. ${ }^{23}$ Exercise SE can reveal another cause for symptoms (e.g. diastolic dysfunction, $\mathrm{PH}$, or dynamic MR) but evidence in support of this indication is lacking.

Exercise SE rather than pharmacological SE is recommended for assessment of symptoms. Supine bicycle exercise is most appropriate for the assessment of contractile reserve, because images can be acquired at both low and high workloads.

Images should be acquired at baseline and immediately post-exercise when using a treadmill, and at baseline, low workload, and peak exercise when using a supine bicycle. For both indications, the minimum acquired dataset comprises LV views, TR CW Doppler for estimation of SPAP, and color flow Doppler to detect MR, obtained in this order. The sequence of image acquisition always depends on the relative importance of the available information and the likelihood of the persistence of abnormalities into recovery. ${ }^{4,19}$

\section{Impact on Treatment}

ESC/EACTS and AHA/ACC guidelines consider aortic valve replacement (AVR) class I indication, level of evidence $B$, in patients with severe $A R$ and symptoms revealed by exercise testing. ${ }^{42,43}$

\section{Mitral Stenosis}

In mitral stenosis (MS), SE demonstrates the haemodynamic significance of the disease, which can contrast with its anatomically defined severity based on valve area. This could be explained by the indexed valve area being low 
for the patient or by valve noncompliance to the increase in flow during stress. $\mathrm{SE}$ is recommended for the assessment of patients with both severe asymptomatic disease and nonsevere disease with symptoms ${ }^{22,23}$ based on extensive evidence. ${ }^{50-55}$

\section{Severe Mitral Stenosis without Symptoms}

MS is defined as severe when the valve area is $<1 \mathrm{~cm}^{2}$ in the ESC/EACTS guidelines ${ }^{22}$ or when the valve area is $<1.5 \mathrm{~cm}^{2}$ in the ACC/AHA guidelines. ${ }^{22}$ This difference has little implication for management because, when the valve area is $<1.5 \mathrm{~cm}^{2}$, the guidelines recommend consideration of the suitability of the valve for balloon valvotomy. Exercise testing is indicated to reveal symptoms when the valve area is $<1 \mathrm{~cm}^{2}{ }^{22,23}$ If the valve is suitable for balloon valvotomy, $\mathrm{SE}$ is indicated to reveal symptoms and assess haemodynamic consequences when the valve area is $<1.5 \mathrm{~cm}^{2}$ but $>1 \mathrm{~cm}^{2} .23,55$ Regardless of suitability for balloon valvotomy, when the valve area is $1.5 \mathrm{~cm}^{2}$ but $>1 \mathrm{~cm}^{2}$, SE is indicated when planning pregnancy or major surgery. 22,23

\section{Non-severe Mitral Stenosis with Symptoms}

$\mathrm{SE}$ is indicated to assess the haemodynamic significance of MS, which if severe, may account for symptoms. ${ }^{50,} 56 \mathrm{MS}$ is diagnosed as severe if the mean gradient is $>15 \mathrm{mmHg}$ on exertion or $>18 \mathrm{mmHg}$ during dobutamine infusion. ${ }^{52,53} \mathrm{An}$ SPAP is $>60 \mathrm{mmHg}$ on exertion is another marker of haemodynamically significant MS.

Exercise echo provides concomitant mitral valve gradient and SPAP assessment. Early increase in SPAP, at low-level exercise, should be looked for since it is correlated with higher rate of exercise-induced symptoms in asymptomatic patients with mitral valve area d" $1.5 \mathrm{~cm}^{2} .52$ Dobutamine SE can be used to assess mitral valve gradients during stress if the patient cannot exercise, but it is not recommended for assessment of SPAP.

Images should be acquired at baseline and immediately post-exercise when using a treadmill; at baseline, low dose and peak when using dobutamine; and at baseline, low workload and peak when using supine bicycle exercise. The minimum acquired dataset comprises TR CW
Doppler for estimation of SPAP and mitral valve CW Doppler for gradient measurement. ${ }^{4}$

Maximal sweep speed and minimal velocity scale should be used for mitral valve continuous Doppler acquisition. In case of atrial fibrillation, $\mathrm{SE}$ is better performed during continuation of rate control medication to avoid early rise in heart rate during the test. ${ }^{4}$

Impact on Treatment

ESC/EACTS and AHA/ACC guidelines consider symptomatic MS as a class I indication for intervention, but suitability for percutaneous balloon valvotomy plays a central role in the final decision to treat. $^{22,23}$

\section{Aortic Stenosis}

Asymptomatic Severe Aortic Stenosis

In patients with aortic stenosis (AS), the onset of symptoms and/or LV systolic dysfunction represents a clear indication (Class I, level of evidence B) for AVR. Exercise testing is contraindicated in patients with severe AS with definite or probable cardiac symptoms. However, exercise testing is recommended to unmask symptoms or abnormal blood pressure responses in patients with AS who claim to be asymptomatic. ${ }^{22,23}$ Approximately one-third of patients exhibit exercise-limiting symptoms; these patients have worse outcomes. ${ }^{57,58}$ Exercise testing, with appropriate physician supervision and close monitoring of the ECG and blood pressure, is safe in AS patients without apparent symptoms. In patients with asymptomatic severe AS (Stage C1 in ACC/AHA guidelines), ${ }^{23}$ exercise $\mathrm{SE}$ has been shown to provide incremental prognostic value beyond exercise testing alone. ${ }^{58,59}$

Images should be acquired at baseline and immediately post-exercise when using a treadmill or at low and peak workload when using supine bicycle exercise. The minimum acquired dataset includes aortic valve CW Doppler for measurement of peak aortic velocity and mean gradient, acquisition of apical four- and twochamber views for the assessment of LVEF by biplane Simpson, then TR CW Doppler for estimation of SPAP . Continuous wave Doppler should ideally be performed from the window from which the maximum velocity was obtained at rest. ${ }^{4}$ 
An increase in mean aortic pressure gradient by e" $18-20 \mathrm{mmHg},{ }^{58,59}$ the absence or limitation of $\mathrm{LV}$ functional reserve (decrease or no change in LVEF suggesting subclinical LV dysfunction), ${ }^{57,60}$ and induced PH (SPAP > $60 \mathrm{mmHg})^{61}$ during exercise are markers of poor prognosis.

The increase in mean gradient may reflect either the presence of more severe AS or a noncompliant rigid aortic valve. ${ }^{58,59}$ The lack of $\mathrm{LV}$ functional reserve with exercise may reflect more advanced disease with LV afterload mismatch and/or exhaustion of coronary flow reserve with exercise. LVEF lacks sensitivity to detect subclinical LV systolic dysfunction and assessment of longitudinal LV strain seems to be a more powerful parameter in predicting the occurrence of symptoms, exercise intolerance, and cardiac events in asymptomatic AS patients with preserved LVEF. ${ }^{62}$ Further studies are needed to determine the best cut-point value of exercise-induced change in LVEF or global longitudinal strain to identify patients at increased risk of developing symptoms, LV systolic dysfunction, or cardiac events. ${ }^{4}$

\section{Impact on Treatment}

The increase in mean gradient may be considered an indication for early elective AVR (Class IIb recommendation, level of evidence C in ESC/EACTS guidelines) in asymptomatic patients with severe AS. ${ }^{22}$ Patients with severe AS developing $\mathrm{PH}$ or with limited contractile reserve and those with moderate AS having a marked increase in pressure gradient during exercise should probably have closer clinical and echocardiographic follow-up. ${ }^{58-62}$

\section{Low-flow, Low-gradient $A S$}

Low-flow, low-gradient (LF-LG) AS may occur with depressed (i.e. classical LF-LG) or preserved (i.e. paradoxical LF-LG) LVEF. ${ }^{63}$ In both cases, the decrease in gradient relative to AS severity is due to a reduction in transvalvular flow. The main challenge in LF-LG AS is to distinguish between patients with true-severe AS and thus usually benefiting from surgical or transcatheter AVR, vs. patients with pseudo-severe AS who may not necessarily benefit from this intervention. Furthermore, patients with LF-LG severe AS have poor outcomes with conservative management but increased operative risk with surgical AVR. 63-69

Low-flow, Low-gradient AS with Reduced LV Ejection Fraction

Classical LF-LG AS is defined as an aortic valve area (AVA) $<1.0 \mathrm{~cm}^{2}$, a mean gradient $<40 \mathrm{mmHg}$ and an LVEF $<50 \% .{ }^{42,43}$ Low-dose dobutamine $\mathrm{SE}$ is useful in these patients to assess stenosis severity and LV functional reserve. ${ }^{64}$

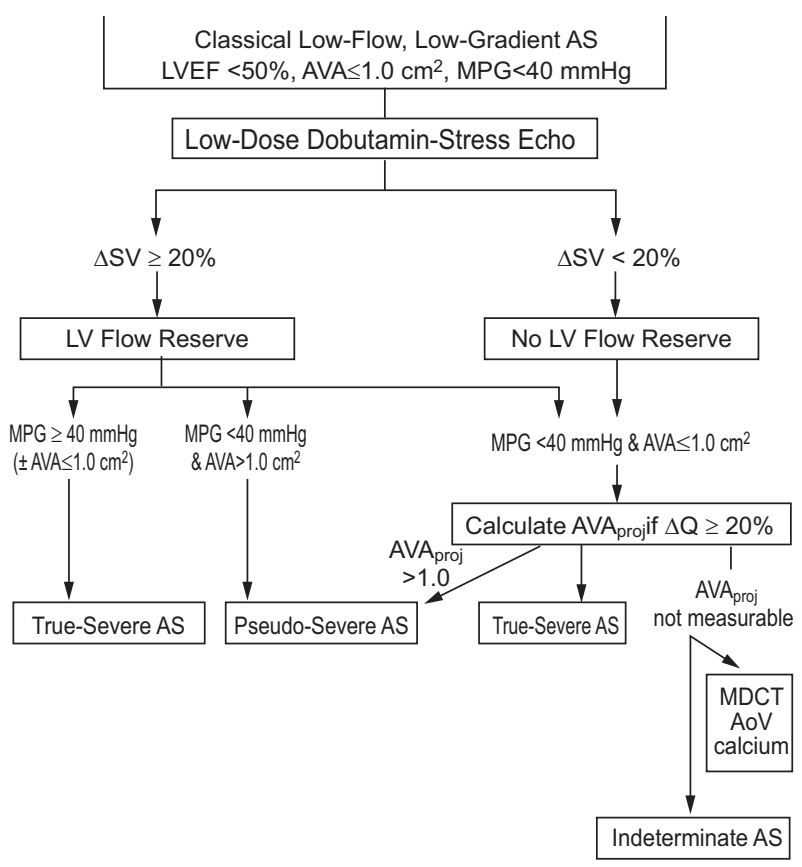

Fig.-2: 4,64: Interpretation of the dobutamine $S E$ results in patients with low-flow, low-gradient $A S$, and reduced $L V E F$. The first step is to determine the presence of flow reserve, which is generally defined as a relative increase in stroke volume $(S V)>20 \%$. If there is flow reserve, the peak effective aortic valve area (AVA) remains $<1 \mathrm{~cm} 2$ and the mean pressure gradient (MPG) exceeds $40 \mathrm{mmHg}$, the stenosis is considered severe. If there is no flow reserve, it is difficult to get a definitive answer with regard to stenosis severity. In this case, the use of projected AVA or the evaluation of calcium score by computed tomography (MDCT)) should be considered. The estimation of the projected AVA may not be reliable when theDQis $<20 \%$. If the projected $A V A$ is $<1 \mathrm{~cm} 2$, the stenosis is severe. $M P G$, mean pressure gradient; $Q$, flow rate; $S V$, stroke volume 
After acquisition at rest, Doppler tracings and LV images are obtained at each dobutamine infusion stage ; the dose increment is delayed until all recordings are considered optimal. The minimum acquired dataset comprises: aortic valve CW Doppler, LVOT PW Doppler (sample volume should be placed as much as possible at the same position in the LVOT during test), views of LV cavity in parasternal long-axis, and apical two- and four-chamber. The imaging assessment includes LV function (changes in EF or global strain) and flow reserve (increase in stroke volume $\geq 20 \%$ ), changes in pressure gradients, and AVA. In contrast to the stroke volume, the mean transvalvular flow rate (i.e. stroke volume/LV ejection time), which is, besides the AVA, the main physiological determinant of the increase in gradient, continues to increase at higher doses of dobutamine due to increase in heart rate. ${ }^{64}$ For this reason, stopping the test when heart rate increases by e" $10 \mathrm{bpm}$, as proposed by some, may preclude significant increase in flow rate and thus limit the ability to distinguish true from pseudo-severe stenosis. ${ }^{70}$

Absence of LV flow reserve during dobutamine $\mathrm{SE}$ is observed in approximately one-third of patients and is associated with high operative mortality (6-33\%) with surgical AVR. ${ }^{64,65}$ However, this factor does not predict absence of LV function improvement in symptomatic status, and late survival after surgery. ${ }^{65,66}$ Thus, the absence of LV flow reserve should not preclude consideration for surgical or transcatheter AVR. ${ }^{65}$ The lack of stroke volume increase during dobutamine SE can result from: (i) afterload mismatch due to an imbalance between the severity of the stenosis and myocardial reserve, (ii) inadequate increase of myocardial blood flow due to associated coronary artery disease, and/or (iii) irreversible myocardial damage due to previous myocardial infarction or extensive myocardial fibrosis. ${ }^{64}$

The peak stress values of stroke volume index, LVEF, or longitudinal strain (LV functional reserve) obtained during dobutamine SE may be better than the absolute or relative changes in these parameters because the peak stress values represent a composite measure accounting for both baseline resting $\mathrm{LV}$ function and LV functional reserve. ${ }^{67-69}$
Typically in true-severe AS, marked increases in gradients with small or no increases in AVA are observed during dobutamine SE, whereas in pseudo-severe AS, gradients increase only slightly or do not change and the AVA increases significantly with dobutamine SE.The most important parameters and criteria to identify true-severe AS during dobutamine SE are: a mean pressure gradient $\geq 40 \mathrm{mmHg}$ or peak aortic jet velocity $\geq 4 \mathrm{~m} / \mathrm{s}$ with an AVA $<1.0 \mathrm{~cm}^{2}$. Pseudo-severe AS is generally defined as a peak stress mean pressure gradient $<40 \mathrm{mmHg}$ and a peak stress AVA $>1.0 \mathrm{~cm}^{2}$. Some studies suggest that the cut-point value of peak stress AVA should be raised from 1.0 to $1.2 \mathrm{~cm}^{2}$ based on the concept that a moderate-to-severe AS may be well tolerated by a patient with preserved LVEF but may be detrimental for a patient with a depressed LVEF. ${ }^{69,70}$ When the AVA-gradient discordance and thus the uncertainty about actual stenosis severity persist with dobutamine $\mathrm{SE}$ (i.e. peak stress gradient $<40 \mathrm{mmHg}$ and peak stress AVA $<1.0 \mathrm{~cm}^{2}$ ), it is helpful to calculate the projected AVA at normal flow rate $(Q)$ (i.e. $250 \mathrm{~mL} / \mathrm{s}$ ) using the formula ${ }^{4,70,71}$ :

Projected AVA $=$ AVArest $+(\triangle \mathrm{AVA} / \triangle \mathrm{Q}) \mathrm{x}$ (250-Qrest) where $\mathrm{AVA}_{\text {rest }}$ and $Q_{\text {rest }}$ are the AVA and mean transvalvular flow rate measured at rest and $\ddot{A A V A}$ and $\ddot{\mathrm{A}} Q$ are the absolute changes in AVA and $Q$ measured during dobutamine SE.

\section{Impact on Treatment}

Patients with pseudo-severe stenosis have no indication for AVR but require optimization of HF therapy and close echocardiographic followup. ${ }^{22,23,72}$ AVR should be considered in patients with evidence of true-severe AS on dobutamine SE. According to ESC/EACTS and ACC/AHA guidelines, ${ }^{22,23}$ symptomatic patients with classical LF-LG AS and evidence of severe AS on dobutamine SE (Stage D2) have a class IIa, level of evidence $\mathrm{C}$, indication for AVR. ${ }^{22,23}$ However, patients with no LV flow reserve have high operative risk and therefore, the ESC/ EACTS guidelines provided a weaker recommendation (IIb, level of evidence C) for AVR in these patients. Less invasive procedures such as transcatheter AVR could be considered in these patients with no LV flow/functional reserve and evidence of severe AS. ${ }^{4}$ 
Low-flow, Low-gradient AS with Preserved Ejection Fraction

Paradoxical LF-LG AS is defined as LVEF $\geq 50 \%$, stroke volume index $<35 \mathrm{~mL} / \mathrm{m}^{2}$, an AVA $<1.0 \mathrm{~cm}^{2}$, indexed AVA $<0.6 \mathrm{~cm}^{2} / \mathrm{m}^{2}$, and mean gradient $<40 \mathrm{mmHg}$ at rest. ${ }^{22,23}$ Recent studies ${ }^{73}$ suggest that exercise- (in patients with no/mild/ ambiguous symptoms) or low-dose dobutamine(in symptomatic patients) SE may be useful in patients with paradoxical LF-LG AS to corroborate stenosis severity. The same parameters and criteria as those described for classical LF-LG AS can be applied. About onethird of the patients with paradoxical LF-LG AS have pseudo-severe stenosis, which is similar to what has been reported in patients with classical LF-LG AS. ${ }^{73}$ However, dobutamine SE is often not feasible or inconclusive in patients with paradoxical LF-LG AS due to the presence of LV restrictive physiology pattern. If such is the case, aortic valve calcium scoring by multidetector computed tomography may be used to confirm stenosis severity. According to ESC/EACTS and ACC/AHA guidelines, ${ }^{22,23}$ symptomatic patients with paradoxical LF-LG AS and evidence of severe AS (Stage D3) have a class IIa, level of evidence $\mathrm{C}$, indication for AVR.

\section{Multivalvular Heart Disease}

Although assessment of multivalvular disease is technically challenging clinically as well as with imaging, SE is well suited for this assessment. Mixed stenotic and regurgitant lesions can be assessed with a combination of colour flow imaging and Doppler, and multiple valves can be systematically assessed during exercise. Limited data, however, exist regarding the assessment and management of patients with multivalvular disease. ${ }^{22,74}$

Evaluation of multivalvular disease with $\mathrm{SE}$ is indicated when the patient's symptoms are disproportionate to the resting haemodynamics. ${ }^{22,23}$ In this case, exercise testing can uncover an explanation for symptoms, e.g. the gradient or regurgitation increases or $\mathrm{PH}$ develops. When the valve disease is severe but the patient is asymptomatic, exercise testing may uncover an abnormal haemodynamic response, arrhythmia, marked ST-segment shifts, or may demonstrate that the patient is indeed limited by symptoms. ${ }^{4}$

Bicycle stress testing is best suited for the evaluation of multivalvular disease, as multiple valves can be assessed during exercise, rather than during recovery ${ }^{4}$.

The strategy for assessment of the valves should be based on the rest echocardiographic images, including a sequence for interrogation of each valve of interest. There is usually one dominant lesion and the strategy of valve interrogation must take this into consideration. It may be necessary to prolong the stages of exercise from 2 or $3-5$ min to complete the indicated colour flow and Doppler assessment. It is valuable to assess haemodynamic changes occurring during the early stages of exercise, especially in patients who are limited by exertional symptoms that may abruptly result in inability to exercise further. ${ }^{52}$ Exercise flow augmentation is known to differ for the mitral and aortic valves; the mean mitral orifice area increases with exercise, whereas increases in stroke volume at the level of the aortic valve are mediated by increases in the aortic time velocity integral. Rheumatic mitral valve disease may include both stenosis and regurgitation and the relative importance of these lesions may vary during exercise; recognition of this is important for treatment. Similarly, in aortic valve disease with combined stenosis and regurgitation, the consequences of the combination may be additive. ${ }^{4}$

\section{Post Heart Valve Procedures}

$\mathrm{SE}$ is a valuable tool for the evaluation of prosthetic valve haemodynamic function and may be useful when there is discordance between the patient's symptomatic status and the prosthetic valve haemodynamics. In patients with no, mild, or equivocal symptoms, the preferred modality is exercise SE using a protocol with graded bicycle exercise performed in the semi-supine position. ${ }^{19}$ Low-dose (up to $20 \mathrm{ig} / \mathrm{kg} / \mathrm{min}$ ) dobutamine SE is used in patients with moderate or severe symptoms. ${ }^{4}$

\section{Aortic and Mitral Prosthetic Valves}

Given that most prosthetic valves with normal function cause some degree of stenosis, the resting values of transprosthetic velocity and gradient overlap considerably between the 
normally and abnormally functioning prostheses. ${ }^{76-79}$ However, with the increase in flow achieved during exercise or dobutamine SE, patients with significant prosthetic valve stenosis or prosthesis-patient mismatch (PPM) will generally show a marked increase in transprosthetic gradient often accompanied by the development of pulmonary arterial hypertension $(\mathrm{PH})$ and subsequent impaired exercise capacity. On the other hand, patients with normal prosthetic valve function or with a localized high gradient (bileaflet mechanical valves with higher pressure recovery) usually have minimal increase in gradient during SE. ${ }^{4}$

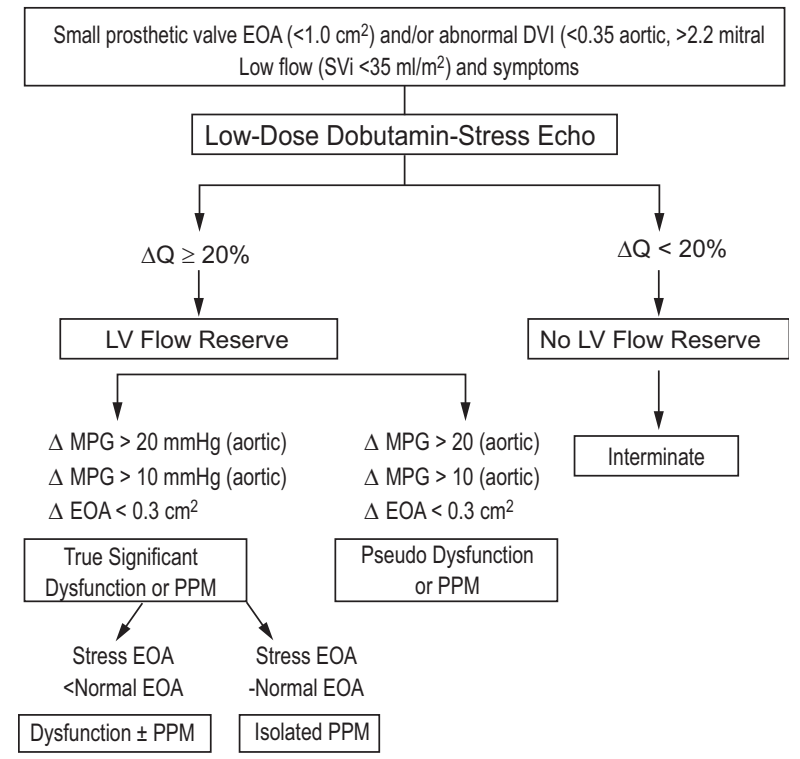

Fig.-3: Evaluation of aortic/mitral prosthetic valves function in patients with low flow. Dobutamine SE is used to distinguish true significant dysfunction or patient-prosthesis mismatch (PPM) vs. pseudo-severe dysfunction or PPM vs. indeterminate valve function.D, difference peak-rest; EOA, effective orifice area; $M P G$, mean pressure gradient; $Q$, flow rate. ${ }^{4,68}$

Exercise or dobutamine SE may be helpful in confirming the presence of haemodynamically significant prosthetic valve stenosis or PPM in patients with mildly to moderately elevated transprosthetic gradients at rest: i.e. between 20 and $40 \mathrm{mmHg}$ in the aortic position or 510 $\mathrm{mmHg}$ in the mitral position. A disproportionate increase in transvalvular gradient $(>20 \mathrm{mmHg}$ for aortic prostheses or $>10 \mathrm{mmHg}$ for mitral prostheses) generally indicates severe prosthesis stenosis (e.g. calcification, pannus overgrowth) or PPM, especially when there is a concomitant rise in SPAP ( $>60 \mathrm{mmHg})$. A potential limitation of SE in this setting is the interference of the prosthetic material with the Doppler signal. This may lead to appearance of spectral Doppler artefacts, therefore, decreasing the accuracy of transprosthetic pressure gradient measurements, especially during exercise. High resting and stress gradients occur more often with smaller ( $\leq 21 \mathrm{~mm}$ for aortic and $\leq 25$ for mitral) and mismatched prostheses. ${ }^{4,80-82}$

Mitral Valve Annuloplasty 4,80-88

In patients with ischaemic MR, restrictive mitral valve annuloplasty may create some degree of functional MS. This abnormality may also occur in patients with degenerative MR following mitral valve repair, especially when complete ring annuloplasty is used. Some degree of functional MS may occur in up to $50 \%$ of patients undergoing mitral valve annuloplasty and this haemodynamic sequel is associated with higher SPAP, worse functional capacity, and poorer quality of life.

Resting Doppler-echocardiographic assessment of mitral valve haemodynamics and SPAP may grossly underestimate the incidence and severity of functional MS following mitral valve annuloplasty because an important proportion of these patients have reduced transmitral flow rate. Indeed, the majority of patients with ischaemic MR have persistent LV systolic dysfunction and thus, LF state after surgery. âBlocker therapy in these patients lengthens diastole and reduces transvalvular flow rate for a given stroke volume, mitigating the impact of significant functional MS.

Exercise or dobutamine SE may be useful to unmask functional MS in patients who underwent mitral valve repair. This test should be considered in patients with resting mean gradient $>3 \mathrm{mmHg}$ who have persistent or recurrent symptoms following surgery. An absolute increase in mean transmitral gradient $\geq 7 \mathrm{mmHg}$ with concomitant peak exercise SPAP $\geq 50 \mathrm{mmHg}$ suggests the presence of functional $\mathrm{MS}^{4}$ 


\section{Summary:}

Exercise SE provides information about disease severity and individual outcome in MR. MR severity, SPAP, and left and right ventricular contractile reserve should be evaluated according to the clinical context. An increase by $\geq 1$ grade in MR (from moderate-to-severe MR), an SPAP $\geq 60 \mathrm{mmHg}$, and a lack of contractile reserve $(<5 \%$ increase in $\mathrm{EF}$ or $<2 \%$ increment in global longitudinal strain) are markers of poor prognosis. In AR, SE is used to assess symptoms, exercise tolerance, and the LV response to stress but not the valve disease severity. A lack of contractile reserve is associated with postoperative LV dysfunction. SE is indicated to reveal symptoms and assess haemodynamic consequences of MS- based on the gradient and SPAP increase during stress-in patients with discordance between symptoms and stenosis severity. Exercise SE is preferred for SPAP assessment. MS should be considered severe if exertion results in a mean gradient $>15 \mathrm{mmHg}$ and SPAP $>60 \mathrm{mmHg}$. In patients with asymptomatic severe AS, exercise SE may uncover the development of symptoms, necessitating consideration for AVR. The main risk markers are a marked (>18-20 $\mathrm{mmHg}$ ) increase in mean pressure gradient, a deterioration of LV systolic function, the lack of LV functional reserve, and the development of $\mathrm{PH}(\mathrm{SPAP}>60 \mathrm{mmHg})$ during exercise. These markers can also be used to adjust the timing of follow-up in patients with moderate AS. In classical low-flow, low-gradient AS with reduced LVEF, a low-dose dobutamine $\mathrm{SE}$ is recommended to: (i) assess LV flow reserve, which is helpful for surgical risk stratification and (ii) differentiate true- from pseudo-severe $\mathrm{AS}$, which is key for guiding the decision to perform AVR. In paradoxical low-flow, lowgradient AS with preserved LVEF, exercise or dobutamine SE may also be used to differentiate true- from pseudo-severe AS. In patients with aortic or mitral prosthetic valves and mild-tomoderate elevation of the resting transprosthetic gradients, exercise SE is useful to confirm: (i) the presence of significant prosthetic valve stenosis or PPM, (ii) the symptomatic status. In patients with aortic or mitral prosthetic valves and LF state with small resting EOA or abnormal Doppler velocity index, low-dose dobutamine SE is useful to differentiate true significant prosthesis dysfunction or PPM vs. pseudo-dysfunction. In symptomatic patients with mitral valve annuloplasty and mild increase in resting transmitral gradients, exercise or dobutamine SE is useful to confirm the presence of functional MS.

Conclusion: Stress echocardiography (SE) is increasingly recognized for its utility in the evaluation of valvular heart disease as it is a unique and highly versatile technique. SE allows for simultaneous assessment of myocardial function and haemodynamics under physiological or pharmacological conditions. The versatility of $\mathrm{SE}$ is great and expanded use is likely. Due to its diagnostic and prognostic value, SE has become widely implemented to assess various conditions of valvular heart diseases; It has thus become essential to establish guidance for its applications and performance in this area.

\section{Conflict of Interest - None.}

\section{References:}

1. Marwick TH. Stress echocardiography. Heart 2003 Jan; 89(1):113-118,

2. Sicari R, Nihoyannopoulos P, Evangelista A, Kasprzak J, Lancellotti P, et al. Stress Echocardiography Expert Consensus Statement-Executive Summary. European Heart Journal 2009; 30, 278-272.

3. Pellikka PA, Nagueh SF, Elhendy AA, et al. American Society of Echocardiography recommendations for performance, interpretation, and application of stress echocardiography. JAm Soc Echocardiogr 2007; 20:1021.

4. Lancellotti P, Pellikka P, Budts W, et al. The Clinical Use of Stress Echocardiography in Non-Ischaemic Heart Disease: Recommendations from the European Association of Cardiovascular Imaging and the American Society of Echocardiography. J Am Soc Echocardiogr 2017;30:101138.

5. Douglas P; Khandheria B ; Stainback R et al. ACCF/ASE/ ACEP/AHA/ASNC/SCAI/SCCT/SCMR 2008 Appropriateness Criteria for Stress Echocardiography. Circulation 2008; 117: 1478-1497.

6. Pierard LA, De Landsheere CM, Berthe C, Rigo P, Kulbertus HE. Identification of viable myocardium by echocardiography during dobutamine infusion in patients with myocardial infarction after thrombolytic therapy: comparison with positron emission tomography. J Am Coll Cardiol 1990; 15: 1021-1031. 
7. Picano E, Sicari R, Landi P, et al. Prognostic value of myocardial viability in medically treated patients with global left ventricular dysfunction early after an acute uncomplicated myocardial infarction: a dobutamine stress echocardiographic study. Circulation 1998; 98: 1078-1084.

8. Picano E. Sustainability of medical imaging. BMJ 2004; 328: 578-580.

9. Gibbons RJ. Leading the elephant out of the corner: the future of health care: presidential address at the American Heart Association 2006 scientific sessions. Circulation 2007; 115: 2221-2230.

10. Wuthiwaropas P, Wiste JA, McCully RB, Kane GC, Scott CG, Pellikka PA. Neuropsychiatric symptoms during 24 hours after dobutamine-atropine stress testing: a prospective study in 1,006 patients. J Am Soc Echocardiogr2011; 24: 367-373.

11. Grunig E, Janssen B, Mereles D, Barth U, Borst M, Vogt I, et al. Abnormal pulmonary artery pressure response in asymptomatic carriers of primary pulmonary hypertension gene. Circulation 2000; 102: 1145-1150.

12. Modesto K, Rainbird A, Klarich K, Mahoney D, Chandrasekaran K, Pellikka P. Comparison of supine bicycle exercise and treadmill exercise Doppler echocardiography in evaluation of patients with coronary artery disease. Am J Cardiol 2003; 91: 1245-1248.

13. Lewandowski T, Armstrong W, Bach D. Reduced test time by early identification of patients requiring atropine during dobutamine stress echocardiography. J Am Soc Echocardiogr 1998; 11: 236-243.

14. Karagiannis S, Bax J, Elhendy A, Feringa H, Cookinos D, van Domburg R, et al. Enhanced sensitivity of dobutamine stress echocardiography by observing wall motion abnormalities during the recovery phase after acute beta blocker administration. Am J Cardiol 2006; 97: 462-465.

15. Chaowalit N, McCully R, Callahan M, Mookadam F, Bailey K, Pellikka P. Outcomes after normal dobutamine stress echocardiography and predictors of adverse events: longterm follow-up of 3014 patients. Eur Heart J 2006; 27: 30393044.

16. Pellikka P, Roger V, Oh J, Seward J, Tajik A. Safety of performing dobutamine stress echocardiography in patients with abdominal aortic aneurysm _ $4 \mathrm{~cm}$ in diameter. Am $J$ Cardiol 1996; 77: 413-416.

17. Takhtehchian D, Novaro G, Barnett G, Griffin B, Pellikka P. Safety of dobutamine stress echocardiography in patients with unruptured intracranial aneurysms. J Am Soc Echocardiogr 2002; 15: 1401-1404.

18. Bremer M, Monahan K, Stussy V, Miller F Jr, Seward J, Pellikka P. Safety of dobutamine stress echocardiography supervised by registered nurse sonographers. J Am Soc Echocardiogr 1998; 11: 601-605.

19. Garbi M, Chambers J, Vannan MA, Lancellotti P. Valve stress echocardiography: a practical guide for referral, procedure, reporting, and clinical implementation of results from the HAVEC Group. JACC Cardiovasc Imaging 2015; 8: 724-736.
20. Picano E, Pibarot P, Lancellotti P, Monin JL, Bonow RO. The emerging role of exercise testing and stress echocardiography in valvular heart disease. J Am Coll Cardiol 2009; 54: 2251-2260.

21. Pierard LA, Lancellotti P. Stress testing in valve disease. Heart 2007; 93: 766-772.

22. Vahanian A, Alfieri O, Andreotti F, Antunes MJ, BaronEsquivias G, Baumgartner H, et al. Guidelines on the management of valvular heart disease. Eur Heart J 2012; 33: 2451-2496.

23. Nishimura RA, Otto CM, Bonow RO, Carabello BA, Erwin JP III, Guyton RA, et al. 2014 AHA/ACC guideline for the management of patients with valvular heart disease. $J A m$ Coll Cardiol 2014; 22: e57-e185.

24. Lancellotti P, Fattouch K, La Canna G. Therapeutic decision-making for patients with fluctuating mitral regurgitation. Nat Rev Cardiol 2015; 12: 212-219.

25. Lancellotti P, Magne J. Stress echocardiography in regurgitant valve disease. Circ Cardiovasc Imaging 2013; 6: 840-849.

26. Izumo M, Suzuki K, Moonen M, Kou S, Shimozato T, Hayashi A, et al. Changes in mitral regurgitation and left ventricular geometry during exercise affect exercise capacity in patients with systolic heart failure. Eur J Echocardiogr 2011; 12: 54-60.

27. Yamano T, Nakatani S, Kanzaki H, Toh N, Amaki M, Tanaka J, et al. Exercise-induced changes of functional mitral regurgitation in asymptomatic or mildly symptomatic patients with idiopathic dilated cardiomyopathy. Am J Cardiol 2008; 102: 481-485.

28. Giga V, Ostojic M, Vujisic-Tesic B, Djordjevic-Dikic A, Stepanovic J, Beleslin B, et al. Exercise-induced changes in mitral regurgitation in patients with prior myocardial infarction and left ventricular dysfunction: relation to mitral deformation and left ventricular function and shape. Eur Heart J 2005; 26: 1860-1865.

29. Lebrun F, Lancellotti P, Piérard LA. Quantitation of functional mitral regurgitation during bicycle exercise in patients with heart failure. J Am Coll Cardiol 2001; 38: 1685-1692.

30. Magne J, Lancellotti P, Pierard LA. Exercise-induced changes in degenerative mitral regurgitation. J Am Coll Cardiol 2010; 56: 300-309.

31. Coisne A, Levy F, Malaquin D, Richardson M, Quéré JP, Montaigne D, et al. Feasibility of Doppler hemodynamic evaluation of primary and secondary mitral regurgitation during exercise echocardiography. Int $J$ Cardiovasc Imaging 2015; 31: 291-299.

32. Magne J, Lancellotti P, Pierard LA. Exercise pulmonary hypertension in asymptomatic degenerative mitral regurgitation. Circulation 2010; 122: 33-41.

33. Magne J, Pibarot P, Sengupta PP, Donal E, Rosenhek R, Lancellotti P. Pulmonary hypertension in valvular disease: a comprehensive review on pathophysiology to therapy from the HAVEC Group. JACC Cardiovasc Imaging 2015; 8: 83-99. 
34. Suzuki K, Izumo M, Yoneyama K, Mizukoshi K, Kamijima $\mathrm{R}$, Kou S, et al. Influence of exercise-induced pulmonary hypertension on exercise capacity in asymptomatic degenerative mitral regurgitation. J Cardiol 2015; 66: $246-252$.

35. Magne J, Donal E, Mahjoub H, Miltner B, Dulgheru R, Thebault C, et al. Impact of exercise pulmonary hypertension on postoperative outcome in primary mitral regurgitation. Heart 2015; 101: 391-396.

36. Kusunose K, Popoviæ ZB, Motoki H, Marwick TH. Prognostic significance of exercise-induced right ventricular dysfunction in asymptomatic degenerative mitral regurgitation. Circ Cardiovasc Imaging 2013; 6: 167-176.

37. Lee R, Haluska B, Leung DY, Case C, Mundy J, Marwick TH. Functional and prognostic implications of left ventricular contractile reserve in patients with asymptomatic severe mitral regurgitation. Heart 2005; 91: 1407-1412.

38. Haluska BA, Short L, Marwick TH. Relationship of ventricular longitudinal function to contractile reserve in patients with mitral regurgitation. Am Heart J 2003; 146: 183-188.

39. Magne J, Mahjoub H, Dulgheru R, Pibarot P, Pierard LA, Lancellotti P. Left ventricular contractile reserve in asymptomatic primary mitral regurgitation. Eur Heart $J$ 2014; 35: 1608-1616.

40. Donal E, Mascle S, Brunet A, Thebault C, Corbineau H, Laurent M, et al. Prediction of left ventricular ejection fraction 6 months after surgical correction of organic mitral regurgitation: the value of exercise echocardiography and deformation imaging. Eur Heart J Cardiovasc Imaging 2012; 13: 922-930.

41. Lancellotti P, Cosyns B, Zacharakis D, Attena E, Van Camp $\mathrm{G}$, Gach O, et al. Importance of left ventricular longitudinal function and functional reserve in patients with degenerative mitral regurgitation: assessment by two-dimensional speckle tracking. J Am Soc Echocardiogr 2008; 21: 13311336.

42. Paraskevaidis IA, Kyrzopoulos S, Tsiapras D, Iliodromitis EK, Parissis J, Farmakis D, et al. The role of left ventricular long-axis contraction in patients with asymptomatic nonischemic mitral valve regurgitation and normal systolic function. Int $J$ Cardiol 2008; 124: 64-71.

43. Piérard LA, Lancellotti P. The role of ischemic mitral regurgitation in the pathogenesis of acute pulmonary edema. NEngl J Med 2004; 351: 1627-1634.

44. Lancellotti P, Lebrun F, Piérard LA. Determinants of exercise-induced changes in mitral regurgitation in patients with coronary artery disease and left ventricular dysfunction. J Am Coll Cardiol 2003; 42: 1921-1928.

45. Lancellotti P, Troisfontaines P, Toussaint AC, Pierard LA. Prognostic importance of exercise-induced changes in mitral regurgitation in patients with chronic ischemic left ventricular dysfunction. Circulation 2003; 108: 1713-1717.
46. Lancellotti P, Gérard PL, Piérard LA. Long-term outcome of patients with heart failure and dynamic functional mitral regurgitation. Eur Heart J 2005; 26: 1528-1532.

47. Lapu-Bula R, Robert A, Van Craeynest D, D'Hondt AM, Gerber BL, Pasquet A, et al. Contribution of exercise-induced mitral regurgitation to exercise stroke volume and exercise capacity in patients with left ventricular systolic dysfunction. Circulation 2002; 106: 1342-1348.

48. Lancellotti P, Magne J, Dulgheru R, Ancion A, Martinez C, Piérard LA. Clinical significance of exercise pulmonary hypertension in secondary mitral regurgitation. Am J Cardiol 2015; 115: 1454-1461.

49. Vinereanu D, Ionescu AA, Fraser AG. Assessment of left ventricular long-axis contraction can detect early myocardial dysfunction in asymptomatic patients with severe aortic regurgitation. Heart 2001; 85: 30-36.

50. Carabello BA. Modern management of mitral stenosis. Circulation 2005; 112: 432-437.

51. Schwammenthal E, Vered Z, Agranat O, Kaplinsky E, Rabinowitz B, Feinberg MS. Impact of atrioventricular compliance on pulmonary artery pressure in mitral stenosis: an exercise echocardiographic study. Circulation 2000; 102: 2378-2384.

52. Brochet E, Détaint D, Fondard O, Tazi-Mezalek A, MessikaZeitoun D, Iung B, et al. Early hemodynamic changes versus peak values: what is more useful to predict occurrence of dyspnea during stress echocardiography in patients with asymptomatic mitral stenosis? J Am Soc Echocardiogr 2011; 24: 392-398.

53. Reis G, Motta MS, Barbosa MM, Esteves WA, Souza SF, Bocchi EA. Dobutamine stress echocardiography for noninvasive assessment and risk stratification of patients with rheumatic mitral stenosis. J Am Coll Cardiol 2004; 43: 393-401.

54. Grimaldi A, Olivotto I, Figini F, Pappalardo F, Capritti E, Ammirati E, et al. Dynamic assessment of 'valvular reserve capacity' in patients with rheumatic mitral stenosis. Eur Heart J Cardiovasc Imaging 2012; 13: 476-482.

55. Aviles RJ, Nishimura RA, Pellikka PA, Andreen KM, Holmes DR Jr. Utility of stress Doppler echocardiography in patients undergoing percutaneous mitral balloon valvotomy. J Am Soc Echocardiogr 2001; 14: 676-681.

56. Baumgartner H, Hung J, Bermejo J, Chambers JB, Evangelista A, Griffin BP, et al. Echocardiographic assessment of valve stenosis: EAE/ASE recommendations for clinical practice. J Am Soc Echocardiogr 2009; 22: 123.

57. Lancellotti P, Karsera D, Tumminello G, Lebois F, Pierard LA. Determinants of an abnormal response to exercise in patients with asymptomatic valvular aortic stenosis. Eur J Echocardiogr 2008; 9: 338-343.

58. Lancellotti P, Lebois F, Simon M, Tombeux C, Chauvel C, Pierard LA. Prognostic importance of quantitative exercise Doppler echocardiography in asymptomatic valvular aortic stenosis. Circulation 2005; 112: I377-I382. 
59. Marechaux S, Hachicha Z, Bellouin A, Dumesnil JG, Meimoun P, Pasquet A, et al. Usefulness of exercise-stress echocardiography for risk stratification of true asymptomatic patients with aortic valve stenosis. Eur Heart J 2010; 31: 1390-1397.

60. Marechaux S, Ennezat PV, LeJemtel TH, Polge AS, de Groote P, Asseman P, et al. Left ventricular response to exercise in aortic stenosis: an exercise echocardiographic study. Echocardiography 2007; 24: 955-959.

61. Lancellotti P, Magne J, Donal E, Dulgheru R, Rosca M, Pierard LA. Determinants and prognostic significance of exercise pulmonary hypertension in asymptomatic severe aortic stenosis. Circulation 2012; 126: 851-859.

62. Donal E, Thebault C, O'Connor K, Veillard D, Rosca M, Pierard L, et al. Impact of aortic stenosis on longitudinal myocardial deformation during exercise. Eur $J$ Echocardiogr 2011; 12: 235-241.

63. Pibarot P, Dumesnil JG. Low-flow, low-gradient aortic stenosis with normal and depressed left ventricular ejection fraction. J Am Coll Cardiol 2012; 60: 1845-1853.

64. Monin JL, Quere JP, Monchi M, Petit H, Baleynaud S, Chauvel C, et al. Low-gradient aortic stenosis: operative risk stratification and predictors for long-term outcome: a multicenter study using dobutamine stress hemodynamics. Circulation 2003; 108: 319-324.

65. Tribouilloy C, Levy F, Rusinaru D, Guéret P, PetitEisenmann H., Baleynaud S, et al. Outcome after aortic valve replacement for low-flow/low-gradient aortic stenosis without contractile reserve on dobutamine stress echocardiography. J Am Coll Cardiol 2009; 53: 1865-1873.

66. Quere JP, Monin JL, Levy F, Petit H, Baleynaud S, Chauvel $\mathrm{C}$, et al. Influence of preoperative left ventricular contractile reserve on postoperative ejection fraction in low-gradient aortic stenosis. Circulation 2006; 113: 1738-1744.

67. Bartko PE, Heinze G, Graf S, Clavel MA, Khorsand A, Bergler-Klein J, et al. Two-dimensional strain for the assessment of left ventricular function in low flow-low gradient aortic stenosis, relationship to hemodynamics and outcome: A substudy of the multicenter TOPAS study. Circ Cardiovasc Imaging 2012; 6: 268-276.

68. Dahou A, Bartko PE, Capoulade R, Clavel MA, Mundigler G, Grondin SL, et al. Usefulness of global left ventricular longitudinal strain for risk stratification in low ejection fraction, low-gradient aortic stenosis: results from the multicenter true or pseudo-severe aortic stenosis study. Circ Cardiovasc Imaging 2015; 8: e002117.

69. Clavel MA, Fuchs C, Burwash IG, Mundigler G, Dumesnil JG, Baumgartner H, et al. Predictors of outcomes in lowflow, low-gradient aortic stenosis: results of the multicenter TOPAS Study. Circulation 2008; 118: S234-S242.

70. Clavel MA, Burwash IG, Mundigler G, Dumesnil JG, Baumgartner H, Bergler-Klein J, et al. Validation of conventional and simplified methods to calculate projected valve area at normal flow rate in patients with low flow, low gradient aortic stenosis: the multicenter TOPAS (True or Pseudo Severe Aortic Stenosis) study. J Am Soc Echocardiogr 2010; 23: 380-386.

71. Blais C, Burwash IG, Mundigler G, Dumesnil JG, Loho N, Rader F, et al. Projected valve area at normal flow rate improves the assessment of stenosis severity in patients with low flow, low-gradient aortic stenosis: The multicenter TOPAS (Truly or Pseudo Severe Aortic Stenosis) study. Circulation 2006; 113: 711-721.

72. Fougères É, Tribouilloy C, Monchi M, Petit-Eisenmann H, Baleynaud S, Pasquet A, et al. Outcomes of pseudo-severe aortic stenosis under conservative treatment. Eur Heart $J$ 2012; 33: 2426-2433.

73. Clavel MA, Ennezat PV, Maréchaux S, Dumesnil JG, Capoulade R, Hachicha Z, et al. Stress echocardiography to assess stenosis severity and predict outcome in patients with paradoxical low-flow, low-gradient aortic stenosis and preserved LVEF. JACC Cardiovasc Imaging 2013; 6: 175183.

74. Unger P, Rosenhek R, Dedobbeleer C, Berrebi A, Lancellotti P. Management of multiple valve disease. Heart 2011; 97: 272-277.

75. Pibarot P, Dumesnil JG. Prosthetic heart valves: selection of the optimal prosthesis and long-term management. Circulation 2009; 119: 1034-1048.

76. Pibarot P, Dumesnil JG. Valve prosthesis-patient mismatch, 1978 to 2011: from original concept to compelling evidence. J Am Coll Cardiol 2012; 60: 1136-1139.

77. Zoghbi WA, Chambers JB, Dumesnil JG, Foster E, Gottdiener JS, Grayburn PA, et al. Recommendations for evaluation of prosthetic valves with echocardiography and Doppler ultrasound. J Am Soc Echocardiogr 2009; 22: 9751014.

78. Lancellotti P, Pibarot P, Chambers JB, Edvardsen T, Delgado V, Dulgheru R, et al. Recommendations for the imaging assessment of prosthetic heart valves. Eur Heart J Cardiovasc Imag 2016; 17: 589-590.

79. Pibarot P, Dumesnil JG, Jobin J, Cartier P, Honos G, Durand LG. Hemodynamic and physical performance during maximal exercise in patients with an aortic bioprosthetic valve. Comparison of stentless versus stented bioprostheses. J Am Coll Cardiol. 1999; 34: 1609-1617.

80. Pibarot P, Dumesnil JG, Jobin J, Lemieux M, Honos G, Durand LG. Usefulness of the indexed effective orifice area at rest in predicting an increase in gradient during maximum exercise in patients with a bioprosthesis in the aortic valve position. Am J Cardiol 1999; 83: 542-546.

81. Magne J, Sénéchal M, Mathieu P, Dumesnil JG, Dagenais F, Pibarot P. Restrictive annuloplasty for ischemic mitral regurgitation may induce functional mitral stenosis. J Am Coll Cardiol 2008; 51: 1692-1701.

82. Kubota K, Otsuji Y, Ueno T, Koriyama C, Levine RA, Sakata R, et al. Functional mitral stenosis after surgical annuloplasty for ischemic mitral regurgitation: importance of subvalvular tethering in the mechanism and dynamic deterioration during exertion. J Thorac Cardiovasc Surg 2010; 140: 617-623. 
83. Kainuma S, Taniguchi K, Daimon T, Sakaguchi T, Funatsu $\mathrm{T}$, Kondoh H, et al. Does stringent restrictive annuloplasty for functional mitral regurgitation cause functional mitral stenosis and pulmonary hypertension? Circulation 2011; 124: S97-S106.

84. Rubino AS, Onorati F, Santarpia G, Achille F, Lorusso R, Santini F, et al. Impact of increased transmitral gradients after undersized annuloplasty for chronic ischemic mitral regurgitation. Int J Cardiol 2012; 158: 71-77.

85. Nishida H, Takahara Y, Takeuchi S, Mogi K. Mitral stenosis after mitral valve repair using the duran flexible annuloplasty ring for degenerative mitral regurgitation. $J$ Heart Valve Dis 2005; 14: 563-564.
86. Chan KL, Chen SY, Chan V, Hay K, Mesana T, Lam BK. Functional significance of elevated mitral gradients after repair for degenerative mitral regurgitation. Circ Cardiovasc Imaging 2013; 6: 1041-1047.

87. Bertrand PB, Verbrugge FH, Verhaert D, Smeets CJ, Grieten L, Mullens W, et al. Mitral valve area during exercise after restrictive mitral valve annuloplasty: importance of diastolic anterior leaflet tethering. $\mathrm{J} \mathrm{Am} \mathrm{Coll}$ Cardiol 2015; 65: 452-461.

88. Bertrand PB, Gutermann H, Smeets CJ, Van Kerrebroeck C, Verhaert D, Vandervoort P, et al. Functional impact of transmitral gradients at rest and during exercise after restrictive annuloplasty for ischemic mitral regurgitation. J Thorac Cardiovasc Surg 2014; 148: 183-187. 